Journal of Environmental
Analysis and Progress
ISSN: $2525-815 \mathrm{X}$

\title{
Produção e qualidade de beterrabas submetidas a diferentes manejos de adubação e efeito residual na produção de milho cultivado em sucessão
}

\section{Yield and quality of sugar beets submitted to different fertilization management and residual effect on succession maize production}

\begin{abstract}
Fabrício Resende de Aguiar ${ }^{1}$, André Cabral França ${ }^{1}$, Rafaele de Sousa Cruz ${ }^{1}$, Levy Tadin Sardinha ${ }^{1}$, Caroline Maira Miranda Machado ${ }^{1}$, Brendo de Oliveira Ferreira ${ }^{1}$, Fausto Henrique Vieira Araújo ${ }^{1}$

${ }^{a}$ Universidade Federal dos Vales do Jequitinhonha e Mucuri-UFVJM, Departamento de Ciências Agrárias, Campus JK. Rodovia MGT 367 - Km 583, $\mathrm{n}^{\circ}$ 5.000, Alto da Jacuba, Diamantina-MG, Brasil. CEP: 39100-000. E-mail: fabricio.r.a@hotmail.com, cabralfranca@yahoo.com.br, rafaelesousacruz@outlook.com, levy.tadin@yahoo.com.br, carolmaira40@gmail.com, brendoagro@gmail.com, faustonura@gmail.com.
\end{abstract}

\begin{tabular}{|c|c|}
\hline ARTICLE INFO & A B S T RACT \\
\hline $\begin{array}{l}\text { Recebido 26 Dez } 2019 \\
\text { Aceito 25 Fev } 2021 \\
\text { Publicado 04 Mar } 2021\end{array}$ & $\begin{array}{l}\text { The successively growing maize to beet has shown positive economic returns to } \\
\text { producers, being fertilization one of the primary factors in obtaining success in } \\
\text { practice. The study aimed to evaluate different fertilization management in } \\
\text { quantitative and qualitative aspects in beet crops and its residual effects on the } \\
\text { succession of corn planted in succession. The experiment was conducted in the } \\
\text { municipality of Diamantina-MG, in a greenhouse; a randomized block design with } \\
\text { seven treatments was used, with different types of fertilizers: control without } \\
\text { fertilization, conventional mineral, pelletized organomineral NPK } 04-17-07 \text { at the } \\
\text { doses of } 40,80,160 \text { and } 320 \% \text { of the recommendation for the beet crop, with four } \\
\text { repetitions. Plant height, the longitudinal and cross-sectional diameter of roots, } \\
\text { chlorophyll A and B, shoot and root fresh and dry matter, productivity, soluble solids } \\
\text { content, and shelf life were evaluated. In the second experimental stage, the number } \\
\text { of ears per plant, weight per ear, weight of the cob, weight of } 100 \text { grains, and the } \\
\text { estimated yield were verified. Data were submitted to variance analysis and Tukey } \\
\text { test (p < 0.05) for average comparison. Regression analysis was performed } \\
\text { considering the doses of organomineral fertilizer for the yield of both crops. It was } \\
\text { concluded that pelletized organomineral fertilizer and filter cake in the planting } \\
\text { provide positive effects to the development and production of sugar beet plants and } \\
\text { the corn in succession, thus showing viable alternatives to mineral fertilization in this } \\
\text { system. }\end{array}$ \\
\hline
\end{tabular}

Keywords: Organic fertilization, mineral, organomineral, Beta vulgaris, Zea Mays, successive cultivate.

\section{R E S U M O}

A prática do cultivo de milho sucessivo à beterraba tem apresentado retornos econômicos positivos aos produtores, sendo um dos fatores primordiais para o sucesso da atividade, a adubação. $\mathrm{O}$ estudo objetivou avaliar diferentes manejos de adubação nos aspectos quantitativos e qualitativos na cultura da beterraba, bem como seus efeitos residuais no cultivo do milho plantado em sucessão. O experimento foi conduzido no município de Diamantina-MG, em casa de vegetação, sob delineamento em blocos casualizados, com sete tratamentos, sendo controle (sem adubação), mineral, organomineral peletizado NPK 04-17-07 nas doses de 40, 80, 160 e $320 \%$ da recomendação para a cultura da beterraba, com quatro repetições. Avaliou-se altura de plantas, diâmetros longitudinal e transversal das raízes, clorofila A e B, peso de massa fresca e seca da parte aérea e raízes, produtividade, teor de sólidos solúveis e o tempo de prateleira. Na segunda etapa experimental, verificou- 
se o número de espigas por planta, peso por espiga, peso do sabugo, peso de 100 grãos e estimada a produtividade. Os dados foram submetidos à análise de variância e ao teste Tukey $(\mathrm{p}<0,05)$ para comparação de médias. A análise de regressão foi feita diante as doses do fertilizante organomineral para produtividade de ambas as culturas. A utilização do fertilizante organomineral peletizado e torta de filtro no plantio proporcionam efeitos positivos ao desenvolvimento e produção de plantas de beterraba assim como para o milho em sucessão, mostrando-se alternativas viáveis à adubação mineral neste sistema.

Palavras-Chave: Adubação orgânica, mineral, organomineral, Beta vulgaris, Zea Mays, cultivo sucessivo.

\section{Introdução}

A beterraba (Beta vulgaris L.) situa-se na $13^{\text {a }}$ posição do ranking das principais hortaliças cultivadas no Brasil em referência ao valor econômico de sua produção (Souza et al., 2003). Sua utilização pode-se dar nas mais diversas formas, consumindo-se tanto a raiz, devido ao seu sabor adocicado e agradável ao paladar, quanto as folhas em saladas. Além das características sensoriais peculiares, sua composição nutricional abrange elevados níveis de substâncias antioxidantes, mostrando-se cada vez mais presente nas refeições do dia a dia dos brasileiros (Lacerda, 2014; Aquino et al., 2006).

No Brasil, segundo o Censo Agropecuário (IBGE, 2017), existem 24.951 estabelecimentos agrícolas produtores de beterraba. Cerca de $80 \%$ da produção nacional concentra-se em cinco principais Estados: São Paulo (23,76\%), Minas Gerais $(21,43 \%)$, Rio Grande do Sul $(13,86 \%)$, Paraná $(10,71 \%)$ e Bahia $(10,46 \%)$.

Originária da Europa, a integrante da família Quenopodiácea responde com melhor desenvolvimento em condições de temperaturas baixas ou amenas. Portanto, tem-se preferido seu cultivo durante o período outono-inverno na maioria das regiões produtoras, principalmente naquelas situadas em baixa altitude (Filgueira, 2013).

Nestas condições, a cultura do milho no cultivo sucessivo ao da tuberosa tem sido uma alternativa viável aos produtores, onde ambas as culturas se destacam pela capacidade de gerenciamento e o alto nível tecnológico empregado em suas atividades. São utilizados insumos modernos, sementes de alta qualidade e com elevado potencial de produção, tolerância a estresses, resistência a diferentes patógenos, atributos físicos, fisiológicos e sanitários adequados.

Entre as tecnologias disponíveis no meio agrícola, a adubação é considerada de extrema relevância e pode vir a ser um fator limitante ao incremento na produtividade e, consequentemente, no rendimento econômico obtido ao final do ciclo.

Encontra-se na literatura vários estudos que relatam os efeitos positivos da adubação NPK à resposta benéficas nos componentes de produção das características agronômicas quantitativas e qualitativas afim de atender as exigências do mercado consumidor.

Com isso, o uso de fertilizantes tem-se intensificado tornando-se cada vez mais expressiva, diante a um custo adicional ao produtor que muitas vezes inviabiliza a atividade. $\mathrm{O}$ alto investimento é ainda mais substancial em solos tropicais uma vez que, em sua maioria, apresentam baixos teores fósforo disponível às plantas (Richardson, 2000).

Em virtude da escassez de matérias-primas para produção de fertilizantes minerais e ao incentivo à conscientização ambiental nestes últimos anos, tem-se buscado assim o reaproveitamento de resíduos urbanos, industriais e agrícolas. Neste cenário, novas tecnologias vêm sendo inseridas no mercado afim de aumentar a eficiência e reduzir nas despesas com insumos. Neste cenário, tem-se hoje os fertilizantes organominerais cuja característica principal consequente da associação mineral ao composto orgânico mostra-se com liberação gradual dos nutrientes e potencial efeito residual no solo, assim como condicionador deste meio (Cardoso, Luz \& Lana, 2015; Profiro, 2016).

Dessa forma, objetivou-se com este estudo avaliar o efeito dos fertilizantes organominerais nos aspectos quantitativos e qualitativos na cultura da beterraba, bem como o efeito residual da adubação da tuberosa na cultura do milho plantado em sucessão.

\section{Material e Métodos}

O experimento foi realizado no período de abril/2018 a fevereiro/2019, em casa de vegetação, no Departamento de Agronomia, no campus JK da Universidade Federal dos Vales do Jequitinhonha e Mucuri-UFVJM, em Diamantina-MG, sob as coordenadas geográficas $18^{\circ} 12^{\prime} 01^{\prime \prime} \mathrm{S}, 43^{\circ} 34^{\prime} 20^{\prime}$ ' $\mathrm{W}$, a $1.400 \mathrm{~m}$ de altitude.

Os canteiros foram preparados mecanicamente nas dimensões $1,20 \mathrm{~m}$ de largura $\mathrm{x}$ $15 \mathrm{~m}$ de comprimento $\mathrm{x} 0,30 \mathrm{~m}$ de altura. Antes da instalação do ensaio foi realizada a coleta da amostra de solo representativa da camada arável 
(0-20 cm), apresentando os seguintes resultados: $\mathrm{pH}$ em água $=6,21 ; \mathrm{P}=6,02 \mathrm{mg} \mathrm{dm}^{-3} ; \mathrm{K}=26,59$ $\mathrm{mg} \mathrm{dm}{ }^{-3} ; \mathrm{Ca}=1,46 \mathrm{cmol}_{\mathrm{c}} \mathrm{dm}^{-3} ; \mathrm{Mg}=0,49 \mathrm{cmol}_{\mathrm{c}}$ $\mathrm{dm}^{-3} ; \mathrm{Al}=0,02 \mathrm{cmol}_{\mathrm{c}} \mathrm{dm}^{-3} ; \mathrm{H}+\mathrm{Al}=2,18 \mathrm{cmol}_{\mathrm{c}} \mathrm{dm}^{-}$ 3; $\mathrm{SB}=2,02 \mathrm{cmol}_{\mathrm{c}} \mathrm{dm}^{-3} ; \mathrm{t}=2,04 \mathrm{cmol}_{\mathrm{c}} \mathrm{dm}^{-3} ; \mathrm{T}=$ $4,20 \mathrm{cmol}_{\mathrm{c}} \mathrm{dm}^{-3} ; \mathrm{m}=1 \% ; \mathrm{V}=48 \%$; Teor de argila $=10 \%$; Teor de silte $=6 \%$; Teor de areia $=84 \%$; $\mathrm{M} . \mathrm{O}=0,70 \mathrm{dag} \mathrm{kg}^{1}$, sendo classificado como Neossolo Quartzarênico, segundo o SiBCS (Embrapa, 2013).

Foram aplicadas $50 \mathrm{t} \mathrm{ha}^{-1}$ de esterco bovino, com posterior incorporação em todas as parcelas experimentais, 60 dias antes do transplantio das mudas, segundo recomendação de Casali (1999), para o cultivo de beterraba em solos arenosos.

As mudas foram produzidas em bandejas de 128 células e conduzidas em casa de vegetação, sob irrigação por nebulização intermitente, três vezes ao dia, até atingirem dois pares de folhas completas, em torno de 30 dias, com posterior transplantio para os canteiros.

$\mathrm{O}$ experimento foi conduzido sob delineamento de blocos ao acaso, com sete tratamentos e quatro repetições, totalizando 28 unidades experimentais, cada uma com 18 plantas, sendo a parcela útil composta pelas quatro plantas centrais. Os tratamentos consistiram em diferentes tipos de adubação: testemunha, tratamento mineral, torta de filtro e organomineral peletizado (04-1707 ), nas doses de $40 \%, 80 \%, 160 \%$ e $320 \%$ da recomendação de $\mathrm{P}_{2} \mathrm{O}_{5}$ para a cultura da beterraba. Foi utilizada a cultivar de beterraba "Early Wonder Tall Top", sob espaçamento $20 \times 20 \mathrm{~cm}$.

A torta de filtro utilizada apresentou as seguintes características físico-químicas: $\mathrm{pH}=$ 7.82; Umidade $=48,57 \%$; Carbono orgânico $=$ 14,38\%; Relação $\mathrm{C} / \mathrm{N}=26,38$ - expressos em base úmida $-\mathrm{N}$ total $=1,06 \% ; \mathrm{P}_{2} \mathrm{O}_{5}$ total $=2,90 \% ; \mathrm{K}_{2} \mathrm{O}$ solúvel em água $=0,80 \%$; Cálcio $=2.67 \%$; Magnésio $=0.40 \%$; Enxofre $=0.15 \%$; Ferro $=$ $2.62 \%$; Manganês $=0.06 \%$; Zinco $=0,01 \%$; Cobre e boro $=<0,01 \%$ - expressos em base seca .

Os cálculos para adubação foram determinados a partir da análise de solo, segundo as recomendações de Casali (1999), para a cultura da beterraba, nas quantidades de $110 \mathrm{~kg} \mathrm{ha}^{-1} \mathrm{de} \mathrm{N}$, $300 \mathrm{~kg} \mathrm{ha}^{-1}$ de $\mathrm{P}_{2} \mathrm{O}_{5}$ e $240 \mathrm{~kg} \mathrm{ha}^{-1}$ de $\mathrm{K}_{2} \mathrm{O}$.

Foram aplicados no plantio $70 \mathrm{~kg} \mathrm{ha}^{-1} \mathrm{de}$ $\mathrm{N}, 300 \mathrm{~kg} \mathrm{ha}^{-1}$ de $\mathrm{P}_{2} \mathrm{O}_{5}$ e 123,5 kg ha ${ }^{-1}$ de $\mathrm{K}_{2} \mathrm{O}$, em linha. Em cobertura, fez-se o parcelamento em duas aplicações, aos 15 dias após o transplantio notado o pegamento das mudas, e aos 35 dias após o transplantio, até o início do desenvolvimento da parte tuberosa (Filgueira, 2013), com $70 \mathrm{~kg}$ de $\mathrm{N} \mathrm{e}$ $58,3 \mathrm{~kg}$ de $\mathrm{K}_{2} \mathrm{O}$ por aplicação.
Utilizou-se sulfato de amônio e cloreto de potássio nas aplicações em cobertura para os tratamentos mineral e organomineral. Para o tratamento orgânico, manteve-se a adubação com torta de filtro, na quantidade de $1887 \mathrm{~kg} \mathrm{ha}^{-1}$, com adição de $74.5 \mathrm{~kg} \mathrm{ha}^{-1}$ de cloreto de potássio visando suprir a quantidade necessária do nutriente. $\mathrm{O}$ tratamento controle permaneceu sem adubação.

A colheita foi realizada aos 80 dias após o transplantio, avaliando-se a altura de plantas, medindo-se do nível do solo até a extremidade da folha mais alta, expressa em $\mathrm{cm}$; peso da massa fresca da parte aérea e raiz, expressa em gramas; peso da massa seca da parte aérea e raiz, expressa em gramas, determinada após secagem em estufa à $65^{\circ} \mathrm{C}$, até atingir peso constante; produtividade, estimada a partir do peso de massa fresca da raiz das quatro plantas coletadas e a densidade populacional utilizada, expressa em toneladas por hectare; clorofilas A e B, a partir da média de três leituras realizadas na folha mediana da planta, com o equipamento ClorofiLOG CFL1030; diâmetro transversal e longitudinal dos tubérculos utilizando-se paquímetro digital, em $\mathrm{cm}$; teor de sólidos solúveis, por refratômetro analógico, expresso em graus brix, e tempo de prateleira, a partir da mensuração diária do peso das amostras submetidas à armazenagem, sob temperatura controlada à $25^{\circ} \mathrm{C}$, por um período de 14 dias.

Finalizada a primeira etapa experimental, realizou-se a semeadura direta do milho híbrido cultivar Feroz Viptera 3 Syngenta ${ }^{\circledR}$ nas parcelas submetidas à adubação para beterraba. Foram semeadas cinco sementes por metro linear, com uma fileira por parcela.

A adubação de cobertura não foi adotada nesta segunda etapa experimental, almejando avaliar o efeito residual das diferentes fontes de fertilizante na cultura de sucessão.

Foram realizadas capinas periódicas para o controle de plantas daninhas e monitoramento de pragas e doenças durante todo o período experimental.

A colheita do milho foi realizada 120 dias após a semeadura, quando os grãos apresentavam em torno de 12 a $13 \%$ de umidade, avaliando-se: peso da massa fresca das espigas, grãos, sabugo e do peso de 100 grãos, em balança analítica, expressas em gramas. A partir do peso da massa fresca dos grãos das cinco plantas coletadas e a densidade populacional utilizada, estimou-se a produtividade de grãos, expressa em toneladas por hectare.

Os resultados foram submetidos ao teste $\mathrm{F}$ e à análise de variância, com o programa estatístico SISVAR®, adotando-se o teste estatístico Tukey a 
5\% de probabilidade para comparação dos valores médios. A análise de variância para o efeito da regressão polinomial mostrou-se significativa pelo teste $\mathrm{F}$ para a variável produtividade em ambos os cultivos, obtendo-se a curva de resposta para a mesma, considerando os diferentes níveis de doses testadas do fertilizante organomineral peletizado.

\section{Resultados e Discussão}

O diâmetro transversal da raiz não apresentou diferença estatística significativa para os diferentes manejos de adubação testados. $\mathrm{O}$ mesmo comportamento foi observado para o diâmetro longitudinal, à exceção da testemunha e a aplicação da maior dose do fertilizante organomineral peletizado os quais proporcionaram resultados inferiores aos demais tratamentos, conforme exposto na Tabela 1.

Vários estudos avaliando a resposta de beterraba sob diferentes adubações corroboram estes resultados, verificando pouca influência destes insumos em resposta ao que diz respeito ao diâmetro transversal e longitudinal das raízes (Ambrosano et al., 2004; Campos et al., 2012; Magro, 2012).

Tabela 1. Média dos valores obtidos para os diâmetros longitudinal (DL), transversal (DT) e altura de plantas de beterraba, submetidas a diferentes manejos de adubação. Fonte: Aguiar et al. (2020).

\begin{tabular}{lccc}
\hline \multirow{2}{*}{ Tratamentos } & DL & DT & Altura \\
\cline { 2 - 4 } & \multicolumn{3}{c}{$(\mathbf{c m})$} \\
\hline Testemunha & $4,43 \mathrm{ab}$ & $5,61 \mathrm{a}$ & $9,77 \mathrm{a}$ \\
TF & $4,75 \mathrm{a}$ & $6,01 \mathrm{a}$ & $11,53 \mathrm{a}$ \\
$100 \%$ MIN & $4,61 \mathrm{a}$ & $5,94 \mathrm{a}$ & $10,04 \mathrm{a}$ \\
$40 \%$ OMP & $4,87 \mathrm{a}$ & $5,82 \mathrm{a}$ & $11,04 \mathrm{a}$ \\
$80 \%$ OMP & $5,11 \mathrm{a}$ & $6,48 \mathrm{a}$ & $11,69 \mathrm{a}$ \\
$160 \%$ OM & $4,67 \mathrm{a}$ & $5,85 \mathrm{a}$ & $10,67 \mathrm{a}$ \\
$320 \%$ OMP & $3,82 \mathrm{~b}$ & $5,67 \mathrm{a}$ & $9,52 \mathrm{a}$ \\
\hline CV $(\%)$ & 6,98 & 70 & 16,52 \\
\hline
\end{tabular}

$\mathrm{TF}=$ torta de filtro; $\mathrm{MIN}=$ Mineral; $\mathrm{OM}=$ Organomineral peletizado. Médias seguidas por mesma letra na coluna não diferem entre si pelo teste Tukey a 5\% de significância.

Para a caracterização do tamanho da beterraba, o Programa Brasileiro para a Modernização da Horticultura (CEAGESP) utiliza o maior diâmetro transversal da raiz tuberosa (Tivelli et al., 2011). As beterrabas obtidas neste experimento, independente do tratamento a qual foram submetidas, podem ser classificadas como Extra A (raízes com diâmetro transversal maior ou igual a $50 \mathrm{~mm}$ e menor que $90 \mathrm{~mm}$ ).

Para a maioria dos manejos testados, as médias obtidas para altura de plantas situaram-se dentro do intervalo previamente estipulado para a cultivar, de 45 a $55 \mathrm{~cm}$, exceto para a dose de $320 \%$ do organomineral cujo valor médio observado foi de 40,2 cm, como demonstrado na Tabela 1 .

Os valores de altura média das plantas obtidos neste estudo foram semelhantes aos encontrados por Sediyama et al. (2011), que relataram o valor aproximado de $48,8 \mathrm{~cm}$, em beterraba Early Wonder, com aplicação de cobertura morta e adubação orgânica. Contudo, Marques et al. (2010) e Ambrosano et al. (2004) relataram valores inferiores, de 34,9 e $40,5 \mathrm{~cm}$, respectivamente, em experimento utilizando a mesma cultivar submetida a diferentes sistemas de adubação.

Alves et al. (2008) relatam a relevância da disponibilidade de nitrogênio para o crescimento em altura de plantas de beterraba, constatando redução de até $70 \%$ quando faltoso. Neste contexto em resposta às variáveis teor de clorofila e altura, verifica-se a essencialidade do fornecimento equilibrado deste nutriente onde, sua deficiência tanto quanto o seu excesso, acarretaram piores respostas. No presente experimento, essa variação não se mostrou tão expressiva no tratamento controle quando comparado aos demais tratamentos em detrimento da aplicação prévia de esterco bovino, suprindo parcialmente a exigência do nutriente às plantas, proporcionando ainda um bom desenvolvimento vegetativo.

$\mathrm{O}$ teor de clorofila nas folhas constitui-se de um importante parâmetro para estimativa indireta do estado nutricional nitrogenado da planta (Aquino et al., 2006). Para os teores de clorofila A, a aplicação do organomineral na dosagem recomendada apresentou melhor resultado em relação a adubação mineral convencional e a testemunha. Não foi constatada diferença significativa entre os diferentes tratamentos quanto ao teor de clorofila B.

Os valores de clorofila total obtidos na leitura através do clorofilômetro variaram de 44,14 a 50,94 unidades SPAD, constatados na ausência de adubação e na aplicação de $240 \mathrm{~kg} \mathrm{ha}^{-1}$ de $\mathrm{P}_{2} \mathrm{O}_{5}$ da fonte organomineral, respectivamente, exibidos na Tabela 2. A maior dosagem testada deste mesmo tratamento refletiu em menores teores de clorofila total. Assim sendo, evidencia-se a importância do fornecimento equilibrado de nutrientes às plantas, uma vez que a deficiência tanto quanto o excesso, promoveram resposta negativa à produção de clorofila pela planta.

Tabela 2. Médias dos teores de clorofila (Clo) A, B e total de plantas de beterraba submetidas a diferentes manejos de adubação. Fonte: Aguiar et al. (2020). 


\begin{tabular}{lcrc}
\hline Tratamentos & Clo A & Clo B & Clo total \\
\hline Testemunha. & $34,37 \mathrm{~b}$ & $9,77 \mathrm{a}$ & $44,14 \mathrm{a}$ \\
TF & $37,84 \mathrm{ab}$ & $11,53 \mathrm{a}$ & $49,37 \mathrm{a}$ \\
$100 \%$ MIN & $34,96 \mathrm{~b}$ & $0,04 \mathrm{a}$ & $44,99 \mathrm{a}$ \\
$40 \%$ OMP & $35,62 \mathrm{ab}$ & $11,04 \mathrm{a}$ & $46,66 \mathrm{a}$ \\
$80 \%$ OMP & $39,25 \mathrm{a}$ & $11,69 \mathrm{a}$ & $50,93 \mathrm{a}$ \\
$160 \%$ OMP & $36,63 \mathrm{ab}$ & $10,67 \mathrm{a}$ & $47,29 \mathrm{a}$ \\
$320 \%$ OMP & $34,98 \mathrm{~b}$ & $9,52 \mathrm{a}$ & $44,49 \mathrm{a}$ \\
\hline CV $(\%)$ & 5,02 & 16,52 & 7,09 \\
\hline
\end{tabular}

$\mathrm{TF}=$ torta de filtro; MIN = Mineral; $\mathrm{OMP}=$ Organomineral peletizado. Médias seguidas por mesma letra na coluna não diferem entre si pelo teste Tukey a 5\% de significância.

Aquino et al. (2006) relataram em experimento com plantas de beterraba submetidas a diferentes doses de nitrogênio, teor de clorofila variando de 34,96 a 45,4 unidades SPAD, para a testemunha e dose de $259 \mathrm{~kg} \mathrm{ha}^{-1}$ de $\mathrm{N}$, respectivamente. Contudo, essa diferença pode ser devida ao período de avaliação, no qual os autores apontam ter sido realizada aos 28 dias após o transplantio e, no presente estudo foi efetuada por ocasião da colheita, aos 80 dias após o transplantio.

A produção de biomassa total e da distribuição do peso de massa seca entre a parte aérea e raiz está intimamente relacionado ao rendimento da cultura (Hole et al., 1983). Os valores obtidos para a massa seca da parte aérea e raiz situaram-se nos intervalos de 20,33 a 45,96 g planta $^{-1}$ e 19,10 a 55,43 g planta $^{-1}$, respectivamente, conforme exposto na Tabela 3.

Tabela 3. Média dos valores obtidos para o peso de massa seca da parte aérea (MSPA) e peso de massa seca da raiz (MFR) de plantas de beterraba submetidas a diferentes manejos de adubação. Fonte: Aguiar et al. (2020).

\begin{tabular}{lcc}
\hline Tratamentos & MSPA & MSR \\
& \multicolumn{2}{c}{ (g) } \\
\hline Testemunha & $29,22 \mathrm{bc}$ & $31,60 \mathrm{bc}$ \\
TF & $42,53 \mathrm{ab}$ & $55,43 \mathrm{a}$ \\
$100 \%$ MIN & $35,81 \mathrm{ab}$ & $47,83 \mathrm{ab}$ \\
$40 \%$ OMP & $39,98 \mathrm{ab}$ & $51,23 \mathrm{a}$ \\
$80 \%$ OMP & $45,96 \mathrm{a}$ & $57,19 \mathrm{a}$ \\
$160 \%$ OMP & $34,96 \mathrm{ab}$ & $44,19 \mathrm{ab}$ \\
$320 \%$ OMP & $20,33 \mathrm{c}$ & $19,10 \mathrm{c}$ \\
\hline CV $(\%)$ & 17,34 & 17,36 \\
\hline
\end{tabular}

$\overline{\mathrm{TF}}=$ torta de filtro; MIN = Mineral; $\mathrm{OMP}=$ Organomineral peletizado. Médias seguidas por mesma letra na coluna não diferem entre si pelo teste Tukey a 5\% de significância.

Em avaliação da distribuição do peso de massa seca e produtividade de plantas de beterraba, Guimarães, Echer \& Minami (2002) relatam alta correlação da produção de massa seca entre as partes produtiva e não produtiva das plantas.
Diferentemente dos resultados encontrados neste estudo, os autores relatam valores de massa seca das raízes e da parte aérea tendendo a proporção de 2:1 enquanto neste foram constatados a tendência a proximidade da igualdade (1:1) da variável nas duas partes da planta.

As diferentes adubações, bem como as diferentes doses testadas, influenciaram na produção de massa fresca de ambas as partes da planta. A adubação com fertilizante mineral refletiu em menor produção de massa fresca da parte aérea e raiz quando comparado a torta de filtro e organomineral $80 \%$. Os valores máximos de massa fresca de raiz foram obtidos com aplicação do fertilizante organomineral na dose recomendada, resultando em uma produtividade estimada de $44,7 \mathrm{tha}^{-1}$ de raízes beneficiadas, como pode ser observado na Tabela 4.

Tabela 4. Média dos valores obtidos para o peso de massa fresca da parte aérea (MFPA), peso de massa fresca da raiz (MSR) e produtividade estimada (Prod.) de plantas de beterraba submetidas a diferentes manejos de adubação. Fonte: Aguiar et al. (2020).

\begin{tabular}{lccc}
\hline \multirow{2}{*}{ Tratamentos } & \multicolumn{1}{c}{ MFPA } & MFR & Prod. \\
\cline { 2 - 4 } & \multicolumn{2}{c}{$(\mathbf{g})$} & (t ha $\left.^{-1}\right)$ \\
\hline Testemunha & $143,60 \mathrm{bc}$ & $72,41 \mathrm{c}$ & $32,70 \mathrm{~b}$ \\
TF & $180,02 \mathrm{a}$ & $93,56 \mathrm{a}$ & $44,69 \mathrm{a}$ \\
$100 \%$ MIN & $157,31 \mathrm{bc}$ & $77,35 \mathrm{~cd}$ & $40,94 \mathrm{a}$ \\
$40 \%$ OMP & $160,60 \mathrm{abc}$ & $75,25 \mathrm{c}$ & $40,18 \mathrm{a}$ \\
$80 \%$ OMP & $179,22 \mathrm{a}$ & $107,25 \mathrm{a}$ & $44,72 \mathrm{a}$ \\
$160 \%$ OMP & $164,25 \mathrm{ab}$ & $67,63 \mathrm{ab}$ & $30,42 \mathrm{bc}$ \\
$320 \%$ OMP & $141,82 \mathrm{c}$ & $42,70 \mathrm{~d}$ & $24,22 \mathrm{c}$ \\
\hline CV $(\%)$ & 5,52 & 9,79 & 7,82 \\
\hline
\end{tabular}

$\mathrm{TF}=$ torta de filtro; $\mathrm{MIN}=$ Mineral; $\mathrm{OM}=$ Organomineral peletizado. Médias seguidas por mesma letra na coluna não diferem entre si pelo teste Tukey a 5\% de significância.

As plantas submetidas a adubação mineral, torta de filtro e organomineral na dose de $40 \%$ também apresentaram resultados estatisticamente iguais e satisfatórios. Dentre estes, foi constatado incremento de $9,2 \%$ na produtividade de beterrabas adubadas com torta de filtro e com fertilizante organomineral peletizado na dose de $80 \%$ quando comparada a adubação convencional. Filgueira (2013) aponta grande variação na produtividade média de raízes de beterraba, situando-se entre 20 e $35 \mathrm{t} \mathrm{ha}^{-1}$. Todavia, os valores médios encontrados neste estudo mostram valores superiores aos preconizados pelo autor.

Ambrosano et al. (2004), estudando a produção de beterraba em sistemas de adubação mineral, organomineral, orgânica e homeopática, não verificaram diferenças significativas entre os 
tratamentos quanto a produtividade. Pinto, Pinto \& Teixeira (2004), em experimento com beterraba cultivada sob diferentes manejos de adubação, aponta maior produção no sistema misto, o qual constava de adubação com esterco associado ao NPK mineral.

Dentre os modelos avaliados, a função quadrática apresentou melhor ajuste $\left(\mathrm{R}^{2}=0,61\right)$. Com base na relação funcional entre a produtividade de raízes e crescentes doses de fósforo aplicadas do organomineral NPK 04-17-07, verificou-se máxima produtividade estimada na aplicação da dose de $227,4 \mathrm{~kg}$ de $\mathrm{P}_{2} \mathrm{O}_{5}$, refletindo em 38,1 t ha ${ }^{-1}$ de raízes de beterraba, como mostrado na Figura 1.

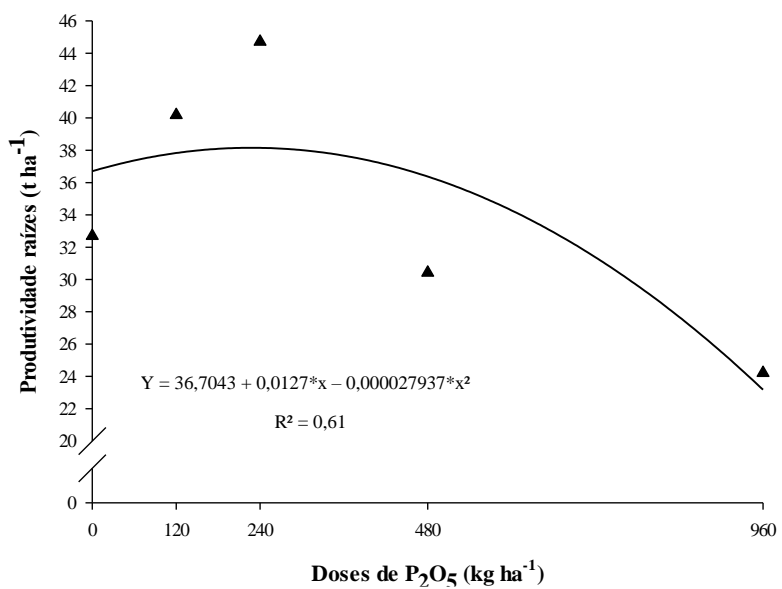

Figura 1. Produtividade de raízes de beterraba ( $t$ ha $\left.{ }^{1}\right)$ em função da aplicação de diferentes doses de $\mathrm{P}_{2} \mathrm{O}_{5}$ do fertilizante organomineral peletizado NPK 04-17-07. Fonte: Aguiar et al. (2020).

Embora observado o comportamento semelhante dos demais regimes testados, ainda assim é possível observar resposta atípica à nutrição organomineral em doses inferiores às requeridas por plantas de beterraba, sobretudo positivo à sua utilização. Verifica-se que os tratamentos organomineral (em dose recomendada e reduzida) e orgânico promoveram valores médios de produtividade estatisticamente iguais aos obtidos utilizando-se da adubação mineral.

Ressalta-se um incremento em valores absolutos de produtividade de, aproximadamente, 3,8 toneladas por hectare de beterrabas nos tratamentos orgânico e organomineral, na dose $80 \%$, quando comparados ao tratamento mineral. Evidenciando-se as condições de baixo teor de argila e matéria orgânica do solo, no qual o experimento foi conduzido, deduz-se que esta diferença se deu, principalmente, em virtude dos efeitos positivos à adição de matéria orgânica no solo através do composto orgânico da torta de filtro, aplicado isoladamente ou como tecnologia empregada no fertilizante organomineral peletizado.

Conforme Profiro (2015), a tecnologia singular de revestimento da fração mineral por polímero orgânico biodegradável empregada neste tipo de fertilizante somam em sua eficiência, em razão da redução de potenciais perdas, a exemplo do nitrogênio e potássio por lixiviação, volatilização do $\mathrm{N}$ amoniacal, além da prevenção do contato direto do fósforo com os óxidos presentes no solo, reduzindo substancialmente a perda de fósforo por fixação. A matriz orgânica neste contida atua também como promotora da atividade microbiana no solo, acarretando na mineralização e liberação lenta dos nutrientes, assim como se aplica a alta produtividade alcançada com a aplicação da torta de filtro.

Reconhece-se a carência de estudos na literatura relacionando o fator adubação à qualidade pós-colheita de produtos agrícolas. Dentre estas, a mensuração do ${ }^{\circ}$ Brix fornece boa estimativa do conteúdo de açúcares no tecido vegetal, característica de grande relevância no aspecto qualitativo da beterraba (Aquino et al., 2006). O teor de sólidos solúveis nas raízes tuberosas não apresentou diferença estatística significativa para os diferentes manejos de adubação testados, conforme demonstrado na Tabela 6.

Tabela 6. Média dos valores obtidos para percentual de água e teor de sólidos solúveis de raízes de plantas de beterraba submetidas a diferentes manejos de adubação. Fonte: Aguiar et al. (2020).

\begin{tabular}{lcc}
\hline Tratamentos & \% de água & ${ }^{\circ}$ Brix \\
\hline Testemunha & 56,36 & $10,03 \mathrm{a}$ \\
TF & 40,75 & $10,39 \mathrm{a}$ \\
$100 \%$ MIN & 38,16 & $9,90 \mathrm{a}$ \\
$40 \%$ OMP & 31,92 & $10,90 \mathrm{a}$ \\
$80 \%$ OMP & 46,68 & $11,20 \mathrm{a}$ \\
$160 \%$ OMP & 34,66 & $10,68 \mathrm{a}$ \\
$320 \%$ OMP & 55,27 & $10,42 \mathrm{a}$ \\
\hline $\mathrm{CV}(\%)$ & - & 9,51 \\
\hline TF $=$ torta de filtro; MIN = Mineral; OM $=$ \\
Organomineral peletizado; Médias seguidas por \\
mesma letra na coluna não diferem entre si pelo \\
teste Tukey a 5\% de significância.
\end{tabular}

Contatou-se variação na faixa de 10,03 a $11,20{ }^{\circ}$ Brix, resultado semelhante aos propostos por Marques et al. (2010) e Batista et al. (2010) em avaliação da produção e qualidade da beterraba em função de diferentes doses e fontes de adubação orgânica. Ambrosano et al. (2004) também constataram a invariabilidade do teor de sólidos solúveis. No entanto, os valores mostraram-se 
inferiores aos obtidos neste estudo, variando de 4,82 a $5,72{ }^{\circ}$ Brix.

Winzer et al. (1996) sugerem que o nitrogênio tem forte influência no teor de sacarose de beterrabas. Lopes (1995) aponta o potencial influente do potássio no teor de sólidos solúveis dos vegetais, aumentando a quantidade de açúcar em beterrabas, assim como relatado por Chitarra (2005) para o abacaxizeiro. Contudo, a aplicação máxima de $266 \mathrm{~kg} \mathrm{ha}^{-1}$ de $\mathrm{N}$ até $511 \mathrm{~kg} \mathrm{ha}^{-1}$ de $_{2} \mathrm{O}$ não foram suficientes para alteração desta variável nas beterrabas. Barreto et al. (2013) também não constataram diferenças significativas para a variável em estudo com duas cultivares de beterraba submetida a diferentes doses de nitrogênio.

No que tange à perda de água das beterrabas ao longo de 14 dias em armazenamento à temperatura ambiente, averiguou-se menores valores de perda de massa fresca nas plantas submetidas a adubação com torta de filtro e organomineral nas doses 40 e $80 \%$, quando comparados aos tratamentos mineral e testemunha, evidenciado na Tabela 5.

O nível máximo de perda de peso aceitável para produtos hortícolas varia em função da espécie e do nível de exigência do mercado consumidor. No entanto, segundo Agrawal \& Srivastava (1987), a beterraba não apresenta aspectos desejáveis na comercialização quando atinge $15 \%$ de perda do seu peso fresco.

As beterrabas atingiram este teor a partir do quarto dia para todos os tratamentos, exceto quanto ao mineral e a maior dose testada do adubo organomineral, verificado na Tabela 7. As produzidas sob aplicação de torta de filtro atingiram este percentual preconizado no em meados do quinto dia.

Tabela 7. Média dos valores obtidos para o número de dias até a raiz comercializável atingir perda de $15 \%$ de massa fresca à temperatura ambiente $\left(25^{\circ} \mathrm{C}\right)$ e percentual da massa fresca mantida após armazenamento no período de 14 dias à temperatura ambiente de raízes de plantas de beterraba submetidas a diferentes manejos de adubação. Fonte: Aguiar et al. (2020).

\begin{tabular}{lcc}
\hline Tratamentos & $\begin{array}{c}\mathbf{N}^{\circ} \text { dias até 15\% } \\
\text { de perda da } \\
\text { MFR }\end{array}$ & $\begin{array}{c}\text { Peso } \\
\text { mantido } \\
\text { após 14 } \\
\text { dias (\%) }\end{array}$ \\
\hline Testemunha & $4,61 \mathrm{abc}$ & $57,82 \mathrm{bc}$ \\
TF & $5,37 \mathrm{a}$ & $65,61 \mathrm{a}$ \\
$100 \%$ MIN & $3,77 \mathrm{bc}$ & $53,85 \mathrm{c}$ \\
$40 \%$ OMP & $4,49 \mathrm{abc}$ & $61,37 \mathrm{ab}$ \\
$80 \%$ OMP & $4,97 \mathrm{ab}$ & $62,16 \mathrm{ab}$ \\
$160 \%$ OMP & $4,10 \mathrm{bc}$ & $55,11 \mathrm{c}$
\end{tabular}

\begin{tabular}{|c|c|c|}
\hline $320 \%$ OMP & $3,59 \mathrm{c}$ & $51,82 \mathrm{c}$ \\
\hline CV (\%) & 11,59 & 4,42 \\
\hline
\end{tabular}

De acordo com Tivelli et al. (2011), a beterraba é constituída por cerce de 90,9\% de água na parte aérea e de $87,3 \%$ na raiz. Analisando a proporção de massa fresca e seca de raízes, podese estimar o percentual de água ali contida. Melhores resultados foram constatados naquelas com menor teor de água, decorrente de menor intensidade da atividade respiratória e maior concentração de açúcares cuja ação como conservante em redução a atividade microbiológica e enzimática é conhecida.

No que diz respeito ao efeito residual dos diferentes manejos de adubação na cultura do milho para segunda etapa experimental, melhores resultados foram constatados na aplicação de 480 $\mathrm{kg} \mathrm{ha}^{-1}$ de $\mathrm{P}_{2} \mathrm{O}_{5}$ quanto ao peso do sabugo, peso de 100 grãos e produtividade estimada. Verificou-se valores médios superiores a duas espigas por planta apenas na adubação organomineral em suas doses superiores à recomendada, não constatando diferença estatística significativa para os demais tratamentos testados.

Os valores médios obtidos nas parcelas submetidas a adubação mineral, orgânica e organomineral na dose de 40 e $80 \%$ à recomendada para a cultura da beterraba não apresentaram diferença estatística significativa no peso por espiga de milho. A este grupo, acrescenta-se àquelas parcelas não adubadas, contudo, com desempenho inferior a torta de filtro. Os valores situaram-se de 97,5 a 146,9 g por espiga. Apenas as maiores doses do fertilizante organomineral refletiram em maior peso por espiga quando comparado a adubação mineral convencional.

Os diferentes manejos de adubação promoveram efeitos significativos com relação ao peso do sabugo. A adubação mineral e organomineral em suas respectivas doses recomendadas refletiram em desempenho semelhantes entre si e superiores à testemunha. A utilização das maiores doses e da torta de filtro destacaram-se em relação aos demais tratamentos testados.

A cultivar de milho utilizada para estudo do estudo em questão preconiza o potencial médio de 32,3 g para massa de 100 grãos. Foi constatada variação de 30 a $41 \mathrm{~g} \mathrm{em}$ resposta às diferentes adubações residuais, cujo maior rendimento se deu naquelas parcelas adubadas na dose de $160 \%$ do fertilizante organomineral. Refletiram em valores 
médios inferiores ao esperado somente na menor dose do fertilizante organomineral e testemunha, evidenciando-se a importância da nutrição adequada para o bom rendimento a cultura, como observado na Tabela 8.

Tabela 8. Média dos valores obtidos para o número de espigas por planta, peso por espiga e peso de 100 grãos de plantas milho cultivadas em sucessão sob efeito residual dos diferentes manejos de adubação testados no cultivo de beterraba. Fonte: Aguiar et al. (2020).

\begin{tabular}{lccc}
\hline Tratamento & $\begin{array}{c}\text { Espiga } \\
\text { spor } \\
\text { planta }\end{array}$ & $\begin{array}{c}\text { Peso por } \\
\text { espiga }\end{array}$ & $\begin{array}{c}\text { Peso de } \\
\text { 100 grãos }\end{array}$ \\
\hline Testemunha & $1,48 \mathrm{c}$ & $97,48 \mathrm{~d}$ & $30,00 \mathrm{~d}$ \\
TF & $1,69 \mathrm{bc}$ & $125,61 \mathrm{abc}$ & $36,25 \mathrm{~b}$ \\
$100 \% \mathrm{MIN}$ & $1,55 \mathrm{c}$ & $102,78 \mathrm{~cd}$ & $32,50 \mathrm{bcd}$ \\
$40 \% \mathrm{OMP}$ & $1,55 \mathrm{c}$ & $105,18 \mathrm{bcd}$ & $30,75 \mathrm{~cd}$ \\
$80 \%$ OMP & $1,81 \mathrm{bc}$ & $113,59 \mathrm{bcd}$ & $34,50 \mathrm{bc}$ \\
$160 \%$ OMP & $2,38 \mathrm{a}$ & $146,91 \mathrm{a}$ & $41,00 \mathrm{a}$ \\
$320 \% \mathrm{OMP}$ & $2,00 \mathrm{ab}$ & $127,32 \mathrm{ab}$ & $35,00 \mathrm{~b}$ \\
\hline $\mathrm{CV}(\%)$ & 9,72 & 8,79 & 4,89 \\
\hline
\end{tabular}

$\mathrm{TF}=$ torta de filtro; $\mathrm{MIN}=$ Mineral; $\mathrm{OM}=$ Organomineral peletizado. Médias seguidas por mesma letra na coluna não diferem entre si pelo teste Tukey a 5\% de significância.

A Tabela 9 mostra que a produtividade média do milho nutrido a partir do efeito residual dos tratamentos testados mostrou-se altamente variável em função das doses e das fontes, com tendência ao comportamento quadrático $(p<0,05)$ para as diferentes quantidades do NPK organomineral. Dentre as doses testadas, refletiu em maior produtividade na aplicação do dobro da dose recomendada de adubação organomineral no plantio para cultura da beterraba, alcançando a margem de 266 sacas por hectare, podendo ser considerada relativamente alta. $\mathrm{O}$ residual da aplicação de metade da dose recomendada para a beterraba através da fonte organomineral também refletiu em resultado relativamente satisfatório, com produtividade aproximada de 160 sacas por hectare.

Tabela 9. Média dos valores obtidos para o peso do sabugo e produtividade estimada de plantas milho cultivadas em sucessão sob efeito residual dos diferentes manejos de adubação testados no cultivo de beterraba. Fonte: Aguiar et al. (2020).

\begin{tabular}{lcc}
\hline Tratamento & $\begin{array}{c}\text { Peso do } \\
\text { sabugo }\end{array}$ & Produtividade \\
\cline { 2 - 3 } & $\mathbf{( g )}$ & $\left(\mathbf{t ~ h a}^{-1}\right)$ \\
\hline Testemunha & $76,50 \mathrm{~d}$ & $6,88 \mathrm{c}$ \\
TF & $118,75 \mathrm{~b}$ & $10,62 \mathrm{ab}$ \\
$100 \% \mathrm{MIN}$ & $96,75 \mathrm{c}$ & $8,10 \mathrm{bc}$
\end{tabular}

\begin{tabular}{lcc}
$40 \%$ OMP & $87,00 \mathrm{~cd}$ & $7,97 \mathrm{bc}$ \\
$80 \%$ OMP & $98,75 \mathrm{c}$ & $8,70 \mathrm{bc}$ \\
$160 \%$ OMP & $156,25 \mathrm{a}$ & $13,27 \mathrm{a}$ \\
$320 \%$ OMP & $120,75 \mathrm{~b}$ & $9,50 \mathrm{bc}$ \\
\hline CV $(\%)$ & 6,04 & 16,96 \\
\hline
\end{tabular}

$\mathrm{TF}=$ torta de filtro; $\mathrm{MIN}=$ Mineral; $\mathrm{OM}=$ Organomineral peletizado. Médias seguidas por mesma letra na coluna não diferem entre si pelo teste Tukey a 5\% de significância.

As parcelas submetidas à adubação orgânica, mineral e organomineral nas doses recomendadas para a cultura da beterraba refletiram em desempenho estatisticamente iguais. No entanto, apesar da análise estatística comparativa, salienta-se o desempenho superior daquelas submetidas à adubação com torta de filtro, cuja produtividade mostrou-se 23,7 e $18 \%$ maior quando comparada aos tratamentos mineral e organomineral, respectivamente, atingindo cerca de 212 sacas de grãos por hectare.

Diante à análise de regressão, verificou-se efeito significativo e tendência de ajuste ao comportamento quadrático do efeito de diferentes doses residuais na produtividade atingida ao final das avaliações. Utilizando-se da derivada da equação exibida na Figura 2, a dose estimada de $584,5 \mathrm{~kg} \mathrm{ha}^{-1}$ de $\mathrm{P}_{2} \mathrm{O}_{5}$ promoveu maior produtividade, alcançando a estimativa aproximada de 12,2 toneladas de grãos por hectare.

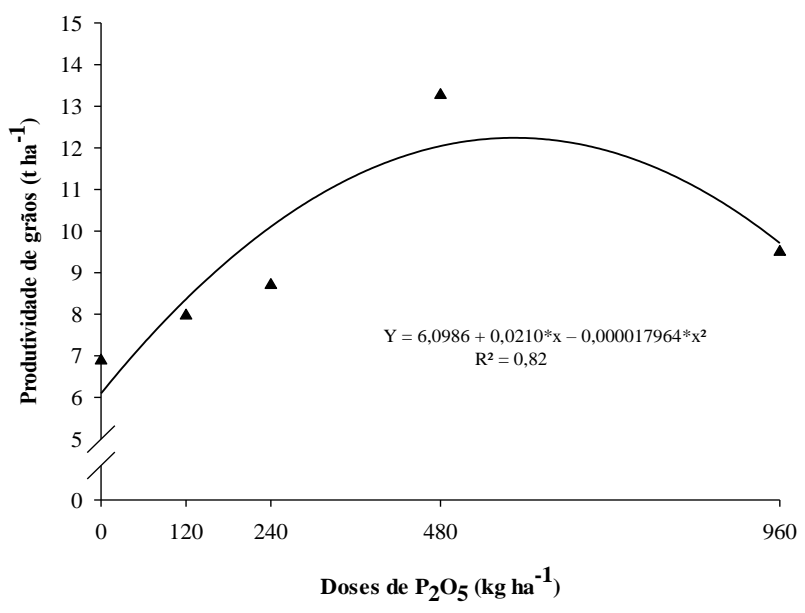

Figura 2. Produtividade de milho grão em sucessão $\left(\mathrm{t} \mathrm{ha}{ }^{-1}\right)$ ao cultivo de beterraba em função de diferentes doses de $\mathrm{P}_{2} \mathrm{O}_{5}$ residual do fertilizante organomineral peletizado NPK 04-17-07 aplicado na ocasião de plantio da olerícola. Fonte: Aguiar et al. (2020).

Deste modo, os resultados obtidos nesta segunda etapa experimental para doses superiores à recomendada do fertilizante organomineral no momento do plantio da beterraba, apresentou resultados positivos apenas em uma segunda safra, 
bem como sua maior dose, evidenciando-se a liberação lenta e potencial efeito residual no solo, benéfico para a cultura sucessiva. Contudo, ambos os tratamentos em suas doses recomendadas demonstraram resultados satisfatórios e até superiores aos relatados na literatura. É pertinente salientar o bom desempenho do fertilizante organomineral na dose de $40 \%$, uma vez que promoveu resultados positivos e satisfatórios sobre dois cultivos testados.

O bom desempenho quanto ao residual resultante da aplicação de torta de filtro pode ser justificado segundo relato de Santos et al. (2011) no qual aponta a possibilidade de substituição parcial, ou até mesmo total, no fósforo requerido pelas plantas, alterando de forma significativa os atributos químicos do solo, elevando a disponibilidade de cálcio, nitrogênio, potássio, além dos teores de carbono orgânico. Estes fatores em associação a matriz mineral sob tecnologia estrutural desenvolvida no processo de fabricação do fertilizante organomineral testado mostrou-se uma alternativa viável à redução da quantidade de fósforo a ser aplicada utilizando a fonte mineral isoladamente.

Em experimento conduzido por Sousa, Henrique \& Korndörfer (2012), investigando o efeito do uso de fertilizante organomineral peletizado sobre a produtividade de híbridos de milho, os autores constataram uma superioridade na utilização do fertilizante organomineral, em relação a adubação convencional, trazendo incrementos na produtividade. Para ambos os híbridos estudados, foram necessários 192 e $457 \mathrm{~kg}$ $\mathrm{ha}^{-1}$ do NPK organomineral 07-18-00 para atingir a mesma produtividade obtida com $400 \mathrm{~kg} \mathrm{ha}^{-1}$ do fertilizante mineral 13-33-00 mostrando-se maior eficiência desta fonte, corroborando os resultados encontrados neste estudo.

Pereira et al. (2012) apontam a promoção ao incremento da produtividade na cultura do milho sob cultivo sucessivo quando utilizado fertilizante organomineral, com a dose NPK $400 \mathrm{~kg}$ $\mathrm{ha}^{-1}$ associada à cama de aviário de 14,8 $\mathrm{t} \mathrm{ha}^{-1}$, alcançando alta produtividade acerca de 209,5 sacas de grãos por hectare.

Martins (2018) também relata efeitos positivos à adubação organomineral, em estudos sobre o efeito da adubação fosfatada de manutenção com fertilizantes organominerais, combinando cama de frango e fosfato solúvel (superfosfato triplo) e reativo de Bayóvar na produção de grãos de milho e feijão, em cultivos sequenciais sob Latossolo Vermelho Distroférrico.

Em contrapartida, Possamai (2016), avaliando a produtividade e alguns caracteres agronômicos da cultura do milho sobre a adubação organomineral e a adubação química, relata a última como a mais vantajosa, quando utilizadas formulações equivalentes para ambas as fontes, cuja justificativa se refletiu na maior estatura de plantas e o incremento médio na produtividade final estimada de $1368 \mathrm{~kg} \mathrm{ha}^{-1}$, quando comparado à adubação organomineral.

Costa et al. (2011), objetivando avaliar o efeito de dois sistemas de culturas e de três fontes de nutrientes no cultivo de milho em Latossolo Vermelho no Estado do Paraná, consistindo em adubação mineral, dejeto de suínos e ambos em conjunto compondo o tratamento organomineral, não verificaram diferença significativa entre os tratamentos. Gomes et al. (2005, citados por Possamai, 2016), também relataram efeitos não significativos na associação de resíduos orgânicos e fertilizante mineral, com uma produtividade semelhante para as referidas fontes.

Gera-se, perante a divergência das inferências de pesquisas encontradas na literatura, a inviabilidade de afirmação dos efeitos positivos observados serem essencialmente das fontes testadas, principalmente no que diz respeito a associação de duas fontes separadas. Portanto, mostra-se necessária a realização de mais pesquisas, em nível de campo, a fim de tornar mais elucidativo o comportamento dos fertilizantes organominerais e seu potencial efeito residual.

\section{Conclusão}

As diferentes fontes testadas em suas respectivas doses recomendadas mostraramse satisfatórias na produção e na qualidade de beterraba, assim como no milho cultivado em sucessão.

A utilização de torta de filtro e do fertilizante organomineral peletizado, nas doses de 40 e $80 \%$, refletiram-se iguais ou mesmo superiores à adubação mineral convencional, mostrando-se como alternativas viáveis para a redução de custos na aquisição de fertilizantes fosfatados.

\section{Agradecimentos}

Os autores agradecem à Universidade Federal dos Vales do Jequitinhonha e Mucuri (UFVJM) pela estrutura e apoio à pesquisa.

\section{Referências}

Agrawal, M. P.; Srivastava, H. M. 1987. Effect of storage temperature on the postharvest quality of sugarbeet. Indian Journal of Agricultural Sciences, 57, (11), 825-828.

Alves, A. U.; Prado, R. M.; Gondim, A. R. O.; Fonseca, I. M.; Cecílio Filho, A. B. 2008. Desenvolvimento e estado nutricional da 
beterraba em função da omissão de nutrientes. Horticultura Brasileira, 26, (2), 292-295.

Ambrosano, J. E.; Rossi, F.; Gulrado, N.; Melo, P. C. T. de; Mendes, P. C. D.; Bréfere, F. A. T.; Ambrosano, G. M. B. A.; Beltrame, K. G. 2004. Produção de beterraba em sistemas com adubação mineral, organomineral, orgânica e orgânica com homeopatia (Phosphorus CH100). Congresso Brasileiro de Olericultura, 44, Campo Grande. Anais eletrônicos. Disponível em: http://www.abhorticultura.com.br/biblioteca/ arquivos/Download/Biblioteca/44_232.pdf.

Acesso em: 25 out. 2018.

Aquino, L. A. de; Puiatti, M.; Pereira, P. R. G; Pereira, F. H. F.; Ladeira, I. R.; Castro M. R. S. 2006. Produtividade, qualidade e estado nutricional da beterraba de mesa e função de doses de nitrogênio. Horticultura Brasileira, 24, (2), 199-203.

Barreto, C. R.; Zanuzo, M. R.; Wobeto, C.; Rosa, C. C. B. da. 2013. Produtividade e qualidade da beterraba em função da aplicação de doses de nitrogênio. Revista Brasileira Multidisciplinar, 16, (1), 145-157.

Batista, M. A. V.; Bezerra Neto, F.; Aroucha, E. M. M.; Ferreira, R. M. de A.; Sousa, C. M. G. de; Silva, M. L. da; Linhares, P. C. F.; Bezerra, A. K. de H.; Barros, G. L. 2010. Características pós-colheita de beterraba submetida a diferentes fontes e doses de adubos verdes. Horticultura Brasileira, 28, (2), 4110-4116.

Campos C. M.; Carvalho, A. A. M.; Golinski, A. L.; Nomelini, Q. S. S.; Golinski, J.; Golynski, A.; Pontes, N. C.; Golynsky, A. A. 2012. Cultivo de beterraba sob diferentes adubações. Horticultura Brasileira, 30, (2), 3637-3643.

Cardoso, A. F.; Luz, J. M. Q.; Lana, R. M. Q. 2015. Produtividade e qualidade de tubérculos de batata em função do fertilizante organomineral e safras de plantio. Revista Caatinga, 28, (4), 80-89.

Casali, V. W. D. 1999. Beterraba. In: Ribeiro A. C.; Guimarães, P. T. G.; Alvarez, V. V. H. (Ed.). Recomendações para o uso de corretivos e fertilizantes em Minas Gerais. $5^{\text {a }}$ aproximação. Viçosa, MG: Comissão de Fertilidade do Solo do Estado de Minas Gerais, 182p.

Chitarra, M. I. F. 2005. Pós-colheita de frutas e hortaliças: Fisiologia e manuseio. Lavras: UFLA, 223p.

Costa, M.S.S. de M.; Steiner, F.; Costa, L. A. de M.; Castoldi, G.; Pivetta, L. A. 2011. Nutrição e produtividade da cultura do milho em sistemas de culturas e fontes de adubação. Revista Ceres, 58, (2), p. 249-255.

EMBRAPA. 2013. Sistema brasileiro de classificação de solos. 3.ed. Brasília. 353p.

Filgueira, F. A. R. 2013. Novo manual de olericultura: agrotecnologia moderna na produção e comercialização de hortaliças. 3 . Ed. rev. e amp. Viçosa, MG: UFV, 421p.

Guimarães, V. F.; Echer, M. M.; Minami, K. 2002. Métodos de produção de mudas, distribuição de matéria seca e produtividade de plantas de beterraba. Horticultura Brasileira, 20, (3), 505-509.

Hole, C. C.; Barnes, A.; Thomas, T. H.; Scott, P. A.; Rankin, W. E. F. 1983. Dry matter distribution between the shoot and storage root of carrot (Daucus carota L.): I. Comparison of Varieties. Annals of Botany, 51, (2), 175-187.

IBGE. 2018. Tabela 819 - Produção, Venda e Valor da produção de horticultura por produtos da horticultura, destino da produção, uso de irrigação, uso de agrotóxicos e uso de adubação. Disponível em: https://sidra.ibge.gov.br/tabela/819. Acesso em: 20 nov. 2018.

Lacerda, Y. E. R. 2014. Produção e qualidade de cenouras e de beterrabas com aplicação de fertilizantes orgânicos. Dissertação (Mestrado), Universidade Estadual da Paraíba. 63p.

Lopes, A. S. 1995. Manual internacional de fertilidade do solo. Associação brasileira para pesquisa da potassa e do fósforo. Piracicaba, $177 \mathrm{p}$.

Magro, F. O. 2012. Efeito do composto orgânico e adubação potássica em atributos do solo e da beterraba. Tese (Doutorado), Universidade Estadual Paulista "Júlio de Mesquita Filho". 116p.

Marques, L. F.; Medeiros, C. D.; Coutinho, O. de L.; Marques, L. F.; Medeiros, C. de B.; Vale, L. S. do. 2010. Produção e qualidade da beterraba em função da adubação com esterco bovino. Revista Brasileira de Agroecologia, 5, (1), 24-31.

Martins, D. C. 2018. Adubação fosfatada organomineral no cultivo de grãos em solos de fertilidade construída. Tese (Doutorado), Universidade Federal de Viçosa, 54p.

Pereira, M. A. M.; Pereira, A. L. S.; Mendes, R. T.; Santos, R. B. S.; Péla, A. 2012. Adubação Organomineral na Cultura do Milho sob Cultivo Consecutivo. In: XXIX Congresso nacional de milho e sorgo - Águas de Lindóia, pp. 1581-1587. 
Pinto, J. de M.; Pinto, R. A.; Teixeira, V. A. 2004. Comportamento da Beterraba (Beta vulgaris) Cultivada em Diferentes Regimes de adubação. Disponível em: http://www.abhorticultura.com.br/biblioteca/ arquivos/Download/Biblioteca/44_328.pdf. Acesso em: 25 nov. 2018.

Possamai, L. 2016. Resposta da cultura do milho à adubação organomineral e adubação química. Revista Cultura Agronômica, 25, (1), 71-78.

Profiro, F. P. 2015. Manual do técnico Geociclo coordenação de produção, $47 \mathrm{p}$.

Richardson, A. E. 2000. Prospects for using soil microrganisms to improve the acquisition of phosphorus by plants. Australian Journal of Plant Physiology, 28, (9), 28, 897-906.

Santos, D. H.; Silva, M. A.; Tiritan, C. S.; Foloni, J. S. S.; Echer, F. R. 2011. Qualidade tecnológica da cana-de-açúcar sob adubação com torta de filtro enriquecida com fosfato solúvel. Revista Brasileira de Engenharia Agrícola e Ambiental, 15, (5), 443-449.

Sediyama. M. A. N.; Santos, M. R.; Vidigal, S. M.; Salgado, L. T. 2011. Produtividade e exportação de nutrientes em beterraba cultivada com cobertura morta e adubação orgânica. Revista Brasileira de Engenharia Agrícola e Ambiental, 15, (9), 883-889.

Sousa, T. X. de; Henrique, H. M.; Korndörfer, G. H. 2012. Uso de fertilizante organomineral e a produtividade de híbridos de milho. In: Teste de performance em híbridos de Milho. Minas Gerais. Disponível em: http://www.geociclo.com.br/wpcontent/uploads/2012/07/Lamina-

Geofert_MILHO.pdf. Acesso em: 10 abr. 2019.

Souza, R. J. de; Fontanetti, A.; Fiorini, C. V. A.; Almeida, K. de. 2003. Cultura da beterraba: Cultivo convencional e cultivo orgânico. Lavras: UFLA. 37p.

Tivelli, S. W.; Factor, T. L.; Teramoto, J. R. S.; Fabri, E. G.; Moraes, A. R. A. de; Trani, P. E.; May, A. 2011. Beterraba: do plantio à comercialização. In: Boletim Técnico IAC, 210. Instituto Agronômico de Campinas, 45p.

Winzer, T.; Gertrud, L.; Hans, W. H. 1996. Influence of phloem transport, $\mathrm{N}$-fertilization and ion accumulation on sucrose storage in the taproots of fooder and sugar beet. Journal of Experimental Botany, 47, (7), 863-870. 